\title{
Práticas de uma professora de Educação Física do Ensino Fundamental e suas relações com a aquisição da leitura e escrita
}

\section{Practices of an elementary school physical education teacher and its relationship with the acquisition of reading and writing}

https://doi.org/10.34112/2317-0972a2020v38n78p131-144

\author{
Catia Silvana da Costa ${ }^{1}$ \\ Maria IOLANDA Monteiro ${ }^{2}$
}

Resumo: Com base nas práticas de uma professora de Educação Física do Ensino Fundamental resultantes de uma pesquisa de mestrado, este artigo apresenta contribuições para o processo de aquisição da leitura e da escrita. A dissertação foi desenvolvida mediante um estudo de caso como uma das possibilidades de pesquisa qualitativa. Por se tratar de um recorte, a discussão se fundamentou na natureza das práticas, com foco na organização, fundamentação e avaliação. A investigação elucidou possibilidades de articulação entre as diferentes linguagens subsidiadas pela linguagem corporal, sobretudo a relação entre as estratégias utilizadas pela professora e o fomento à cultura da leitura e escrita. Essas práticas contribuem para o desenvolvimento de conteúdos da Educação Física, para o processo de aquisição da leitura e escrita com base nos pressupostos da inserção dessa disciplina na área de linguagens e, também, para as políticas públicas de formação docente na área educacional.

PALAVRAS-ChAVE: Educação física no ensino fundamental; práticas de leitura e escrita; políticas públicas de formação docente.

ABSTRACT: Based on the practices of a Physical Education teacher from Elementary School resulting from a master's research, this article presents contributions of these practices to the

1. Instituto Federal de Educação, Ciência e Tecnologia de Mato Grosso do Sul, Jardim, MS, Brasil.

2. Universidade Federal de São Carlos, São Carlos, SP, Brasil. 
Práticas de uma professora de Educação Física do Ensino Fundamental e suas relaçães...

process of acquisition of reading and writing. The dissertation was developed through a case study as one of the possibilities for qualitative research. As this is an excerpt, the discussion was based on the nature of the practices, with a focus on organization, reasoning and evaluation. The investigation elucidated possibilities of articulation between the different languages subsidized by body language, especially the relationship between the strategies used by the teacher and the promotion of the culture of reading and writing. These practices contribute to the development of Physical Education content, to the process of acquiring reading and writing based on the assumptions of the insertion of Physical Education in the area of languages and, also, to the public policies of teacher education in Physical Education and Pedagogy. KEYWORDS: Physical education in elementary school; reading and writing practices; public policies for teacher education.

\section{Apresentação}

Apresentamos, neste artigo, uma discussão referente às contribuições das aulas de uma professora iniciante de Educação Física nos anos iniciais do Ensino Fundamental para o processo de aquisição da leitura e da escrita, tomando-se por base os resultados de uma pesquisa de mestrado em educação desenvolvida no período de 2012 a 2013 (COSTA, 2014). O objetivo da dissertação consistiu em conhecer e compreender as práticas pedagógicas dessa professora e as fontes que influenciam na construção dos seus saberes no decurso de sua trajetória profissional.

No caso deste artigo, o objetivo se fundamentou em uma preocupação, identificada na professora, de realização de um trabalho com base em uma perspectiva interdisciplinar, considerando a cultura da leitura e da escrita, porém, sem perder de vista a especificidade da Educação Física.

Esperamos, na análise dos resultados - subsidiados pela natureza das práticas da participante da pesquisa, com ênfase na organização, fundamentação e avaliação dessas mesmas práticas -, apresentar diversas características que contribuem para $\mathrm{o}$ processo de aquisição da leitura e da escrita, embora não tenha sido esse o foco da dissertação e nem tenha sido considerado como especificidade nas práticas analisadas.

A dissertação foi desenvolvida por meio de um estudo de caso com a professora de Educação Física como uma das possibilidades de pesquisa qualitativa (ANDRÉ, 1998), por ser composta por entrevistas e observação participante (BOGDAN; BIKLEN, 1994), constituindo-se em um "estudo descritivo de uma unidade, seja uma escola, um professor, um aluno ou uma sala de aula” (ANDRÉ, 1998, p. 30). 
Recentemente, a Base Nacional Comum Curricular [BNCC] (BRASIL, 2016) apresentou orientações para a construção e aplicabilidade de currículos e Projetos Políticos Pedagógicos (PPP) para a Educação Básica, fundamentadas em "Direitos e Objetivos de Aprendizagem e Desenvolvimento" (estabelecidos com base em "princípios éticos, políticos e estéticos") em articulação, nos níveis federal, estadual e municipal, com políticas e atuações que possibilitem a materialização dos fundamentos e das finalidades que a constituem. Proveniente de uma exigência legal, a BNCC apresenta-se como proposta de melhoria educacional.

A área de linguagens é uma das áreas do conhecimento presentes no documento, e a Educação Física é um dos seus componentes curriculares. Assim, na perspectiva das linguagens, a Educação Física contempla as práticas corporais como "textos culturais passíveis de leitura e produção, não devendo, portanto, ser limitadas apenas à reprodução” (BRASIL, 2016, p. 100). Logo, essa forma de entender a Educação Física possibilita e explica sua inserção na área de linguagens. Outra forma de compreensão da área pode ser identificada em Soares (1996). A autora, em defesa de uma especificidade da Educação Física e de seus conteúdos, reflete sobre o processo de aprendizagem ao longo da vida e a respeito dos diferentes saberes e inúmeros trajetos importantes para a reflexão sobre a disciplina.

Para a autora, a presença da Educação Física na escola, na qualidade de matéria de ensino, origina uma desordem que possui, como característica própria, uma ordem interna que pode contribuir para a criação de uma nova ordem no contexto escolar. Entretanto, para que esse movimento seja possível, faz-se necessário que a especificidade da Educação Física seja preservada, mantida e aprofundada, sem que a área se afaste e/ou se feche em si mesma (SOARES, 1996). Preservar, manter e aprofundar essa especificidade requer, segundo a autora, saber o que é da área e acentuar esse saber para, assim, dominar, recusar, recuperar, destacar, caracterizar, adaptar e produzir, bem como brincar com essa especificidade.

A autora afirma, ainda, a existência de particularidades especiais nas práticas da área, as quais podem apresentar modificações de natureza técnica, científica e cultural, constituindo-se num acervo histórico da humanidade e, por conseguinte, sendo tratadas pedagogicamente, uma vez que compõe $(\mathrm{m}) \mathrm{o}(\mathrm{s})$ conteúdo(s) que o professor de Educação Física deve dominar.

Assim, garantir várias possibilidades de diálogo entre as áreas do conhecimento nos anos iniciais do Ensino Fundamental, para elucidar como uma área pode contribuir para outra, não despreza, em nenhum momento, essa especificidade da Educação 
Práticas de uma professora de Educação Física do Ensino Fundamental e suas relações...

Física defendida por Soares (1996), haja vista que anunciamos, no início deste tópico, que não foi esse o foco da dissertação, nem foi tampouco considerado como especificidade nas práticas analisadas. Com base na natureza das práticas da participante da pesquisa, entendemos que preservar, manter e aprofundar a especificidade da Educação Física não significa não haver diálogo e contribuições entre as áreas.

Como práticas de linguagens, localizamos alguns estudos referentes às contribuições das aulas de Educação Física para o processo de alfabetização nos anos iniciais (CORDEIRO; CORDEIRO, 2015; COSTA; MONTEIRO, 2016).

Embora este artigo apresente diálogos com importantes referências que já defenderam as aulas de Educação Física como potencial espaço para o desenvolvimento da cultura da leitura e da escrita, seu aprofundamento e sua originalidade se assentam na mobilização de referências que defendem a especificidade da Educação Física (COSTA, 2014; SOARES, 1996). Além disso, esse aprofundamento e essa originalidade estão alicerçados na relação entre as estratégias utilizadas nas aulas de Educação Física e o fomento à cultura da leitura e da escrita.

No material desenvolvido pelo Centro de Alfabetização, Leitura e Escrita da Universidade Federal de Minas Gerais (MINAS GERAIS, 2004), por exemplo, encontramos contribuições para os processos de alfabetização e de letramento com base em uma compreensão desses processos por suas diferenças e especificidades, indissociabilidade e imprescindibilidade. A alfabetização é entendida "como o processo específico e indispensável de apropriação do sistema de escrita, a conquista dos princípios alfabético e ortográfico que possibilitam ao aluno ler e escrever com autonomia" e o letramento "como o processo de inserção e participação na cultura escrita” (MINAS GERAIS, 2004, p. 13).

De acordo com Monteiro (2010, p. 23), "a palavra letramento foi introduzida no Brasil a partir da década de 1980, com o objetivo de diferenciar-se do ensino da codificação e decodificação dos sinais gráficos e de ampliar o conceito de alfabetização". Para a autora, os processos de alfabetização e de letramento são diferentes e complementares, e não há possibilidade de formação de leitores competentes sem que a relação entre esses processos seja estabelecida: "essa relação possibilita ainda o uso da língua nas práticas sociais de leitura e escrita não apenas no cotidiano escolar" (MONTEIRO, 2010, p. 25).

No propósito de elucidar possibilidades de diálogos e contribuições de uma área em outra(s), em especial das aulas de Educação Física para o processo de aquisição da leitura e da escrita, organizamos este artigo em quatro tópicos: "Apresentação"; 
"Práticas pedagógicas de uma professora de Educação Física iniciante"; "Natureza das práticas: organização, fundamentação e avaliação"; e "Algumas considerações finais".

Práticas PEDAgógicas de uma PROFESSORA DE EDUCAÇão FísiCa

A dissertação (COSTA, 2014), cujo objetivo consistiu em conhecer e compreender as práticas de uma professora de Educação Física iniciante e as fontes que influenciam na construção dos seus saberes, possibilitou o entendimento de algumas relações entre o ensino da Educação Física e o ensino da leitura e da escrita.

Para o seu desenvolvimento, foram empregados os seguintes instrumentos de coleta de dados: entrevistas semiestruturadas, observação participante e análise documental. Realizadas em quatro momentos da pesquisa, no período de maio de 2012 a março de 2013, as entrevistas tiveram como objetivo investigar a fundo as questões estudadas, informando minuciosamente sobre os problemas analisados (ANDRÉ, 1998).

As observações das práticas da participante foram realizadas, concomitantemente, em duas escolas estaduais, abarcaram o desenvolvimento de noventa aulas e ocorreram ao longo do segundo semestre de 2012. Com base no pressuposto de que existe sempre uma situação de interação entre o pesquisador e a situação investigada, de modo a transformar tal situação e ser por ela também transformado, a observação participante permitiu uma sucessiva ação mútua entre ambos (ANDRÉ, 1998).

Já os documentos foram utilizados para constituir o fato no seu todo, complementando os conhecimentos extraídos dos dados coletados (ANDRÉ, 1998). Os PPP's das escolas, junto à legislação para o ensino da Educação Física nos anos iniciais, ao plano de ensino, ao caderno de planejamento, às atividades, aos livros, aos filmes, aos textos, aos registros dos alunos etc., também foram analisados.

A professora iniciante e as duas escolas envolvidas foram caracterizadas. Por se tratar de um recorte, centralizamos nossas análises na natureza das práticas, com foco na organização, fundamentação e avaliação dessas práticas.

Natureza Das PRÁticas: ORganizaÇão, FUndamentaÇão E AVALIAÇÃo

Nas práticas da professora pesquisada, percebemos atitudes que buscaram favorecer o dinamismo e a interação entre os alunos, a participação ativa de todos, a otimização do tempo da aula e a equidade de oportunidades, ampliando as experiências e os 
Práticas de uma professora de Educação Física do Ensino Fundamental e suas relações...

conhecimentos discentes (COSTA, 2014). Além disso, as contribuições das atividades desenvolvidas colaboravam para as práticas de leitura e escrita.

Na proposição e no desenvolvimento do conteúdo "Jogos de Perseguição", por exemplo, a participante definiu os alunos "pegadores" por meio da cor da roupa, do mês do aniversário e/ou pela primeira letra do nome, bem como organizou os alunos em dois grandes grupos ("pegadores" e "fugitivos") e realizou a inversão das posições, entre outros critérios utilizados. Essas estratégias, além de contemplarem a maioria das intenções presentes nas atitudes da participante, confirmam a promoção de práticas inclusivas e de participação ativa.

A possibilidade de participação ativa nas atividades pelos alunos se coaduna à ideia que concebe o aluno como protagonista em seu próprio processo de aprendizagem, conforme a BNCC (2016), Freire (2010) e Petry (1988). Nessa concepção, observou-se, na participante, o respeito e a valorização das práticas da "cultura corporal" dos alunos mediante a consideração pelos movimentos próprios no desenvolvimento do conteúdo "Ginástica Rítmica" - estudado e vivenciado por meio de filmes, imagens, materiais alternativos e movimentos do cotidiano dos alunos, como cambalhota, parada de mãos, estrela etc. Afirmamos, assim, que as atitudes, os conteúdos e as atividades propostas, as estratégias e as intencionalidades da professora, bem como as possibilidades cinéticas supracitadas, igualmente podem contribuir para potencializar a expressividade da criança nas práticas de leitura e escrita.

Houve valorização das produções dos alunos por meio da sua exposição nos murais das escolas. Antes da exposição, a participante realizou, em parceria com as professoras pedagogas, correções ortográficas em razão da finalidade dessas produções, atitude que corresponde às regras inerentes à cultura escolar e incorporadas por ela, conforme uma das implicações para o professor iniciante apresentadas por Guarnieri (2005) e a uma sólida rede de influência recíproca entre diferentes atores, de acordo com a definição do exercício da docência por Tardif (2008).

O desenvolvimento dos "Jogos de Salão" pela participante exemplifica essa adequação do tempo, dos materiais e dos espaços, a saber: o espaço selecionado para a vivência desses jogos foi o refeitório das escolas, ambiente arejado, com várias mesas e bancos e que favoreceu a participação de todos os alunos ao mesmo tempo; a disposição das mesas e dos bancos possibilitou que os alunos se sentassem em duplas, trios, quartetos ou em grupos maiores; e a proposta da aula e a sua forma de organização promoveu uma dinâmica diferente da sala e da quadra, favorecendo a interação entre os alunos por meio da discussão das regras dos jogos. Além disso, os jogos estudados e vivenciados 
foram apresentados aos alunos juntamente com seus países de origem, proposta que contempla uma perspectiva contextualizada de ensino (SÃO PAULO, 2011).

Para Cordeiro e Cordeiro (2015), a necessidade de ensinar o sistema de escrita desde o início do Ensino Fundamental e a necessidade do desenvolvimento da capacidade para uso desse sistema pela criança em situações variadas de comunicação são elementos que se destacam nos objetivos do Pacto Nacional pela Alfabetização na Idade Certa, PNAIC (BRASIL, 2012), os quais consistem em assegurar a alfabetização plena de todas as crianças até os oito anos de idade. Ainda segundo Cordeiro e Cordeiro (2015, p. 2), a alfabetização ocorre, também, na interação com o meio e com os sujeitos que compõem a realidade, na medida em que se produzem sentidos e significados que auxiliam a compreensão e a maturação das habilidades de leitura e escrita".

Assim, entendemos que a "interação com o meio e com os sujeitos" e a "produção de sentidos e significados" - o que contribui para as práticas de leitura e escrita - são proporcionadas pelas práticas planejadas e desenvolvidas pela participante da pesquisa de mestrado, as quais igualmente fomentam a cultura da leitura e escrita em razão das estratégias utilizadas, a saber: produção de materiais com os alunos nas aulas de Educação Física; diversificação e ampliação da "cultura corporal" dos alunos; valorização de suas produções; otimização de seus processos de aprendizagem; promoção de dinâmicas diferentes da quadra e da sala de aula; e possibilidade de discussão das regras dos jogos pelos alunos.

Desse modo, essas práticas transcendem as questões da leitura e escrita, porque o diálogo, a experimentação, o entendimento e a interação (imprescindíveis na construção do conhecimento) são possibilidades igualmente presentes nas diversas áreas do conhecimento. Logo, afirmamos que algumas características do processo de aquisição da leitura e da escrita também foram contempladas nas práticas pedagógicas desenvolvidas pela professora de Educação Física iniciante.

A transcrição a seguir elucida o desenvolvimento de uma atividade proposta em grupo, na qual os alunos realizaram uma produção textual sobre o tema do "Folclore" com base em frases soltas, cujo objetivo contemplou, concomitantemente, o tema proposto na aula de Educação Física e as questões referentes ao processo de aquisição da leitura e da escrita: "A ideia... de trabalhar desse jeito... é... foi [...] devido às... às atividades que às vezes eu vejo as professoras fazendo em sala" (COSTA, 2014, p. 132).

Igualmente, essa temática foi estudada e vivenciada por meio da proposição de "adivinhas" nas aulas de Educação Física e aprofundada pelas professoras pedagogas 
Práticas de uma professora de Educação Física do Ensino Fundamental e suas relaçães...

mediante a sugestão de pesquisas para serem realizadas pelos alunos e a disponibilização de cartazes com essas "adivinhas" na sala de aula para serem consultados por eles. Essas iniciativas, ainda que isoladas e restritas a algumas docentes da escola, confirmam o aprofundamento de um mesmo assunto em disciplinas, aulas e professores diferentes, cujo propósito incide em estabelecer conexões entre as áreas do conhecimento.

Tomando-se por base as assertivas de Melo (2006), afirmamos que o desenvolvimento dessa temática por meio das atividades apresentadas, além de contemplar uma perspectiva interdisciplinar e subsidiar as práticas de leitura e escrita, cumpre com os desígnios da Educação Física e de outras áreas na escola, apesar de não ser o foco principal da dissertação. Para o autor, a articulação entre as capacidades intelectuais e motoras na alfabetização é importante, uma vez que essas capacidades são indissociáveis, complementares, correlatas e apresentam o mesmo nível de importância. Porém, trajetos tortuosos foram trilhados na tentativa de aproximação entre elas e, em razão desses impasses, faz-se necessário "questionar como a alfabetização ou a educação podem resgatar o valor das atividades corporais e, também, fazer com que elas possam contribuir no processo educacional” (MELO, 2006, p. 70).

A proposição da atividade supracitada, a respeito do "Folclore" revela o posicionamento de mediadora adotado pela participante, a promoção dos alunos como protagonistas na construção do saber, a interação originada pelo trabalho em grupo, a ludicidade e o desenvolvimento da autonomia e da responsabilidade nos alunos.

O desenvolvimento do conteúdo "Jogos, Brinquedos e Brincadeiras Tradicionais" também elucida uma organização da prática baseada em circuitos, com o posicionamento/agrupamento dos materiais por temas e em pontos estratégicos da quadra e o tempo da aula distribuído entre a quantidade de circuitos organizados. Essa forma de organização, focada na aprendizagem discente e na otimização do tempo da aula, favoreceu a vivência dos alunos em todas as atividades por mais tempo. Para realizar o objetivo de contribuir para o processo de alfabetização das crianças por meio da Educação Física, Petry (1988, p. 19) buscou, entre outras finalidades, "trazer para a alfabetização a autoconfiança que elas têm do ponto de vista físico". Para a autora, os avanços nas práticas corporais igualmente sinalizavam avanços nas práticas de alfabetização porque o aperfeiçoamento de certas atividades (sobretudo com foco na coordenação óculo-manual) nas aulas de Educação Física demanda "as mesmas habilidades requeridas na aprendizagem da escrita” (PETRY, 1988, p. 22).

Diante das práticas apresentadas e analisadas, foi possível perceber uma ampliação do entendimento discente a respeito dos conteúdos da Educação Física por meio das 
relações estabelecidas, pela participante e pelos próprios alunos, com outros conteúdos, outras áreas e outros recursos (além dos materiais esportivos geralmente cultuados nas aulas). As duas situações a seguir elucidam essa ampliação e essas relações: na vivência do jogo "Labirinto" houve apresentação de uma possibilidade diferente para a realização da atividade por uma das duplas de alunos, e na vivência do jogo "Yoté", um aluno estabeleceu relação entre o jogo e um texto informativo localizado por ele. Assim, as relações estabelecidas pela participante com outras áreas se efetivam mediante o uso da linguagem como meio para o desenvolvimento de um conteúdo da Educação Física ("Jogos Africanos"), conforme Ladeira (2007).

Dentre as situações observadas, compreendemos que relacionar um jogo com um texto pode ser considerado o desenvolvimento de uma capacidade que fomenta a cultura da leitura e da escrita, com base em estratégias utilizadas nas aulas de Educação Física, sem perder de vista a especificidade da área. O uso da linguagem como meio elucida a preservação, a manutenção e o aprofundamento dessa especificidade, conforme defende Soares (1996), mediante o desenvolvimento nas aulas, por exemplo, de jogos africanos.

Enquanto área de conhecimento, a linguagem se faz presente na organização das etapas de escolarização da BNCC, o que implica em uma forma de entendimento da Educação Física e, ao mesmo tempo, permite e elucida sua inserção na área da linguagem (BRASIL, 2016).

Como exemplo, nas atividades com foco na coordenação óculo-manual, de

lançar e apanhar uma bola, uma bolsinha de areia, um aro no espaço, entram as mesmas operações que consistem em traçar uma linha de um ponto ao outro; lançar e receber permite à criança construir seu sentido espacial, sua habilidade e destreza dos movimentos das mãos e dos dedos (PETRY, 1988, p. 22).

As relações entre conteúdos e temas ("Jogos Africanos" e "Discriminação Racial”) e entre aulas de Educação Física e aulas das professoras pedagogas também foram identificadas. Essas práticas, incomuns na Educação Física (COSTA, 2014; LADEIRA; DARIDO, 2003), propõem a confecção de brinquedos, oportunizam a tomada de decisões, articulam as diferentes linguagens (escrita, gráfica e corporal) e corroboram os pressupostos de Brasil (2016), Ladeira e Darido (2003), Ladeira (2007), São Paulo (2011) e Costa e Monteiro (2016), os quais fundamentam e justificam a inserção da Educação Física na área de linguagens. Essas possibilidades 
Práticas de uma professora de Educação Física do Ensino Fundamental e suas relações...

de articulações entre as diferentes linguagens foram subsidiadas pela linguagem corporal por meio do compromisso com o currículo e com as competências para a leitura e escrita (COSTA, 2014). Para Petry (1988, p. 65-66), "a educação física prepara (e é preparada pela) a alfabetização bem como toda aprendizagem intelectual ou de relação com o mundo da cultura".

Assim, as influências das práticas desenvolvidas pelas professoras pedagogas na escolha das atividades e estratégias utilizadas pela participante da pesquisa de mestrado em suas aulas nos anos iniciais podem ser identificadas concomitantemente ao processo de construção de sua própria identidade profissional no exercício da docência em Educação Física. Práticas realizadas pelos alunos, durante as aulas, como leitura das regras, interpretação das instruções dos jogos, identificação das características das atividades e registro das orientações da professora no caderno contribuem para o processo de aprendizagem da leitura e da escrita. Corroborando Tardif (2008), percebemos as inter-relações que permeiam os saberes construídos pela participante, que são resultado de uma afluência entre o individual e o social.

Nos procedimentos avaliativos, algumas dificuldades foram identificadas, como "participação nas aulas" e habilidades desenvolvidas nas práticas da "cultura corporal”. Para superar tais dificuldades, a participante fez uso de registros que, para ela, funcionaram como medida de segurança e diagnóstico daquilo que os alunos aprenderam. Igualmente, eles confirmaram algumas contribuições de suas aulas: "auxilia muito... na leitura... na escrita... produção de texto [...] na prática também [...] uma brincadeira de corda... que eles possam... cantar uma música... uma parlenda... e... é... saber a sequência... certinha... né... do alfabeto" (COSTA, 2014, p. 137).

Definitivamente, os critérios avaliativos adotados por ela não se assentam na busca por talentos esportivos, e sim nas dimensões do conteúdo desenvolvido, conforme os Parâmetros Curriculares Nacionais (PCN) de Educação Física para o ensino de $1^{\mathrm{a}}$ a $4^{\mathrm{a}}$ série (BRASIL, 1997), a saber: proposição de trabalho e carimbo nos registros realizados no caderno (dimensão conceitual); observação do comportamento (dimensão atitudinal); e observação da participação (dimensão procedimental).

Ferreira e Reali (2009) ratificam a necessidade de políticas públicas quando afirmam que a especificidade da área é representativa das dificuldades apresentadas pelos professores de Educação Física iniciantes. Acrescentamos a essas dificuldades as particularidades do nível de ensino de atuação profissional docente, conforme ilustram os resultados da pesquisa de mestrado. 
Logo, a natureza das práticas desenvolvidas pela participante (permeadas por algumas dificuldades) contém diversas características (elucidadas no último tópico des-

te artigo) que, além de preservar, manter e aprofundar a especificidade da Educação Física, elucidam a relação entre as estratégias utilizadas nas aulas e o fomento à cultura da leitura e da escrita. Por conseguinte, práticas dessa natureza podem contribuir para o diálogo entre as áreas e subsidiar o processo de aquisição da leitura e da escrita.

\section{Algumas considerações finais}

Fundamentadas no objetivo deste artigo, apresentamos algumas características que contribuem para o processo de aquisição da leitura e da escrita com base nas aulas de uma professora de Educação Física iniciante e atuante nos anos iniciais. É válido atentar-se para o fato de que as práticas de leitura e escrita não foram o foco principal da dissertação e tampouco foram consideradas como especificidade das aulas analisadas.

A especificidade da Educação Física, conforme Soares (1996), deve ser preservada, mantida e aprofundada. Corroborando a autora, afirmamos que a participante da pesquisa possui domínio dessa especificidade e, em virtude desse domínio, apresenta atitudes que buscam favorecer o dinamismo, a interação entre os alunos e a participação ativa de todos. Ela adequa o tempo, os materiais e os espaços, desenvolve suas práticas com base em uma perspectiva contextualizada e interdisciplinar de ensino, produz materiais com os alunos nas aulas de Educação Física, coloca-os como protagonistas na construção do saber, utiliza-se de outras áreas como meio para o desenvolvimento de conteúdo específico da Educação Física, oportuniza a tomada de decisões e compromete-se com o currículo e com as competências para a leitura e a escrita. Essas estratégias, identificadas em suas práticas, apoiam, fundamentam e sustentam o processo de ensino e de aprendizagem que desenvolve e, segundo Soares (1996), são conhecimentos da formação profissional que não se configuram como conteúdo.

Assim, ratificamos nosso posicionamento inicial, uma vez que o diálogo e as contribuições entre as áreas não excluem a especificidade da Educação Física, uma vez que, em conformidade com Soares (1996) e Costa (2014), também é nossa intenção defender essa especificidade, bem como a relação entre as estratégias utilizadas nas aulas de Educação Física e o fomento à cultura da leitura e da escrita.

$\mathrm{Na}$ busca de realização do supracitado objetivo, além do diálogo com alguns resultados da dissertação, da identificação de dificuldades e possibilidades de articulação entre componentes curriculares e áreas do conhecimento, foi possível elucidar 
Práticas de uma professora de Educação Física do Ensino Fundamental e suas relações...

essas questões em documentos provenientes de exigência legal, como os PCN e a BNCC, o Currículo do Estado de São Paulo e o caderno de apresentação para a formação do professor alfabetizador do PNAIC, os quais igualmente contribuem para fundamentar e explicar a relação entre os componentes e as áreas, bem como a inserção da Educação Física na área de linguagens. Nessa perspectiva, podem-se visualizar relações entre o ensino da Educação Física e o ensino da leitura e da escrita e contribuições de um componente curricular em outro.

A participante se valeu da proposição do conteúdo fundamentado nas dimensões conceituais, procedimentais e atitudinais (com reflexões para além da especificidade da Educação Física) e da articulação entre as várias linguagens no desenvolvimento de suas aulas. Igualmente, essas opções/ações da participante podem ser explicadas com base nos pressupostos da área de linguagens e na perspectiva do letramento.

Conforme diversos estudos (BRASIL, 2012; CORDEIRO; CORDEIRO, 2015; COSTA; MONTEIRO, 2016; LADEIRA, 2007; LADEIRA; DARIDO, 2003; PETRY, 1988), igualmente confirmamos as possibilidades de articulação entre as áreas e, em especial, as contribuições das aulas de Educação Física para o desenvolvimento do processo de aquisição da leitura e da escrita. Essas possibilidades se justificam na medida em que atendem aos pressupostos que fundamentam a inserção da Educação Física na área de linguagens.

Portanto, as características identificadas nas práticas da participante cooperam, concomitantemente, para o desenvolvimento dos conteúdos da Educação Física e para o processo de aquisição da leitura e da escrita com base nos pressupostos da inserção da Educação Física na área de linguagens, entre outras reflexões. Ademais, as análises realizadas fundamentam o debate a respeito de possibilidades de práticas da natureza das aqui apresentadas no contexto de início da carreira do docente e a necessidade de políticas públicas de formação profissional na área, sobretudo para professores de Educação Física iniciantes e atuantes nos anos iniciais do Ensino Fundamental.

\section{REFERÊNCIAS}

ANDRÉ, M. E. D. A. Etnografia da prática escolar. 2. ed. Campinas: Papirus, 1998. 128 p.

BOGDAN, R.; BIKLEN, S. Investigação Qualitativa em Educação: uma introdução à teoria e aos métodos. Tradução de Maria João Alvarez, Sara Bahia dos Santos e Telmo Mourinho Baptista. Portugal: Porto Editora, 1994. 336 p.

BRASIL. Ministério da Educação. Conselho Nacional de Secretários de Educação. Base Nacional Comum Curricular. Proposta Preliminar. 2. versão revista. Brasília: MEC, CONSED, abr. 2016. 
BRASIL. Ministério da Educação e do Desporto. Parâmetros Curriculares Nacionais: Educação Física (ensino de $1^{a}$. a $4^{\text {a }}$. séries). Brasília, v. 7, 1997.

BRASIL. Secretaria de Educação Básica. Diretoria de Apoio à Gestão Educacional. Pacto nacional pela alfabetização na idade certa: formação do professor alfabetizador: caderno de apresentação. Brasília: MEC, SEB, 2012.

CORDEIRO, S. G.; CORDEIRO, R. V. Educação Física no contexto da alfabetização: pensando relações e possíveis contribuições. In: XIX CONGRESSO BRASILEIRO DE CIÊNCIAS DO ESPORTE (CONBRACE) E VI CONGRESSO INTERNACIONAL DE CIÊNCIAS DO ESPORTE (CONICE) - Territorialidade e diversidade regional no Brasil e América Latina: suas conexões com a Educação Física e ciências do esporte, 19., 2015, Vitória. Anais... Vitória: 2015. p. 1-15. COSTA, C. S. Práticas pedagógicas de uma professora de Educação Física "de início de carreira": um estudo de caso. 2013. Dissertação (Mestrado) - Programa de Pós-Graduação em Educação, Universidade Federal de São Carlos, São Carlos, 2014.

COSTA, C. S.; MONTEIRO, M. I. Educação Física na área de Linguagens, Códigos e suas Tecnologias (LCT): relações e contribuições possíveis. In: X CONGRESSO NACIONAL DE EDUCAÇÃO FÍSICA E XXI REUNIÃO CIENTÍFICA: "Práxis: baseando-se em evidência para revolucionar a prática”, 2016, Bauru. Anais... Bauru: UNESP, 2016.

FERREIRA, L. A.; REALI, A. M. M. R. O início da carreira docente na Educação Física. In: REALI, A. M. M. R.; MIZUKAMI, M. G. N. (Org.). Complexidade da docência e formação continuada de professores. 1. ed. São Carlos: EdUFSCar, 2009. p. 17-43.

FREIRE, J. B. Educação de corpo inteiro: teoria e prática da Educação Física. São Paulo: Scipione didático, 2010. $176 \mathrm{p}$.

GUARNIERI, M. R. O início na carreira docente: pistas para o estudo do trabalho do professor. In: GUARNIERI, M. R. (Org.). Aprendendo a ensinar: o caminho nada suave da docência. 2 Ed. Campinas: Autores Associados; Araraquara: PPG em Educação Escolar da FCL da UNESP, 2005. p. 5-23.

LADEIRA, M. F. T. Linguagem e suas possibilidades na Educação Física escolar. 2007. Dissertação (Mestrado) - Instituto de Biociências, Universidade Estadual Paulista, Rio Claro, 2007.

LADEIRA, M. F. T.; DARIDO, S. C. Educação Física e Linguagem: algumas considerações iniciais. Motriz, Rio Claro, v. 9, n. 1, p. 31-39, jan./abr. 2003. Disponível em: http://www.rc.unesp.br/ib/ efisica/motriz/ogn1/Ladeira.pdf. Acesso em: 10 jul. 2018.

MELO, L. F. Do letramento ao corpo em movimento: um estudo sobre a Educação Física inserida numa proposta de educação. 2006. Dissertação (Mestrado em Educação) - Programa de Pós-Graduação em Educação, Universidade Vale do Rio dos Sinos, São Leopoldo, 2006.

MINAS GERAIS (Estado). Secretaria de Estado da Educação. Orientações para a organização do ciclo inicial de alfabetização. Caderno 2. Belo Horizonte: Centro de Alfabetização, Leitura e Escrita, 2004.

MONTEIRO, M. I. Alfabetização e letramento na fase inicial da escolarização. São Carlos: EdUFSCar, 2010. $117 \mathrm{p}$.

PETRY, R. M. Educação Física e alfabetização. 3. ed. Porto Alegre: Kuarup, 1988. 67 p.

SÃO PAULO (Estado). Secretaria da Educação. Currículo do Estado de São Paulo: linguagens, códigos e suas tecnologias. 2. ed. São Paulo: SE, 2011. 
Práticas de uma professora de Educação Física do Ensino Fundamental e suas relaçães...

SOARES, C. L. Educação Física escolar: conhecimento e especificidade. Rev. Paul. Educ. Fís., São Paulo, supl. 2, p. 6-12, 1996. Disponível em: https://fefd.ufg.br/up/73/o/Texto_65_-_ Educa o_F sica_Escolar_-_Conhecimento_e_Especificidade_-_ Carmem_L__ia_Soares.pdf. Acesso em: 06 jan. 2020.

TARDIF, M. Saberes docentes e formação profissional. Tradução de Francisco Pereira. 9. ed. Petrópolis: Vozes, 2008. $325 \mathrm{p}$.

\section{SOBRE AS AUTORAS}

Catia Silvana da Costa é graduada em Licenciatura Plena em Educação Física (Universidade Estadual do Norte do Paraná), tem Mestrado em Educação (Universidade Federal de São Carlos) e Doutorado em Educação (Universidade Federal de São Carlos). É professora/pesquisadora do Instituto Federal de Educação, Ciência e Tecnologia de Mato Grosso do Sul. Tem experiência na área de Educação e Educação Física Escolar, com pesquisa nos seguintes temas: formação de professores e processos de ensino e de aprendizagem na Educação Básica e no Ensino Superior.

E-mail: catia.costa@ifms.edu.br.

Maria Iolanda Monteiro é graduada em Licenciatura em Pedagogia (Universidade Estadual Paulista Júlio de Mesquita Filho), tem Mestrado em Educação Escolar (Universidade Estadual Paulista Júlio de Mesquita Filho) e Doutorado em Educação (Universidade de São Paulo). É professora/pesquisadora da Universidade Federal de São Carlos. Tem experiência na área de formação docente na modalidade presencial e a distância, com pesquisa nos seguintes temas: práticas e saberes docentes, alfabetização, letramento, variação linguística, educação a distância, formação inicial e continuada de educadores da educação básica. Pertence ao Grupo Horizonte (Grupo de Estudos e Pesquisas sobre Inovação em Educação, Tecnologias e Linguagens).

E-mail:mimonteiro@ufscar.br.

Recebido em 21 de abril de 2019 e aprovado em 02 de abril de 2020. 